\title{
Measurement of the Thickness of the Urethrovaginal Space in Women with or without Vaginal Orgasm
}

\author{
Giovanni Luca Gravina, MD, PhD, * Fulvia Brandetti, MD, ${ }^{*}$ Paolo Martini, MD, PhD, ${ }^{*}$ \\ Eleonora Carosa, MD, PhD, ${ }^{*}$ Savino M. Di Stasi, MD, ${ }^{\dagger}$ Susanna Morano, MD, ${ }^{\ddagger}$ Andrea Lenzi, MD,, and \\ Emmanuele A. Jannini, MD* \\ *Department of Experimental Medicine, University of L'Aquila, L'Aquila, Italy; 'Department of Surgery-Urology, "Tor \\ Vergata" University, Rome, Italy; ‡Department of Clinical Sciences, University of Rome "La Sapienza," Rome, Italy; \\ §Department of Medical Physiopathology, University of Rome "La Sapienza," Rome, Italy
}

DOI: 10.1111/j.1743-6109.2007.00739.x

\begin{abstract}
A B S T R A C T
Introduction. The physiology and anatomy of female sexual function are poorly understood. The differences in sexual function among women may be partly attributed to anatomical factors.

Aim. The purpose of this study was to use ultrasonography to evaluate the anatomical variability of the urethrovaginal space in women with and without vaginal orgasm.

Methods. Twenty healthy, neurologically intact volunteers were recruited from a population of women who were a part of a previous published study. All women underwent a complete urodynamic evaluation and those with clinical and urodynamic urinary incontinence, idiopathic detrusor overactivity, or micturition disorders, as well as postmenopausal women and those with sexual dysfunction were excluded. The reported experience of vaginal orgasm was investigated.
\end{abstract}

Main Outcome Measure. The urethrovaginal space thickness as measured by ultrasound was chosen as the indicator of urogenital anatomical variability. Designated evaluators carried out the measurements in a blinded fashion.

Results. The urethrovaginal space and distal, middle, and proximal urethrovaginal segments were thinner in women without vaginal orgasm. A direct correlation between the presence of vaginal orgasm and the thickness of urethrovaginal space was found. Women with a thicker urethrovaginal space were more likely to experience vaginal orgasm $(r=0.884 ; P=0.015)$. A direct and significant correlation between the thickness of each urethrovaginal segment and the presence of vaginal orgasm was found, with the best correlation observed for the distal segment $(r=0.863 ; P<0.0001)$. Interobserver agreement between the designated evaluators was excellent $(r=0.87$; $P<0.001)$.

Conclusions. The measurement of the space within the anterior vaginal wall by ultrasonography is a simple tool to explore anatomical variability of the human clitoris-urethrovaginal complex, also known as the G-spot, which can be correlated to the ability to experience the vaginally activated orgasm. Gravina GL, Brandetti F, Martini P, Carosa E, Di Stasi SM, Morano S, Lenzi A, and Jannini EA. Measurement of the thickness of the urethrovaginal space in women with or without vaginal orgasm. J Sex Med 2008;5:610-618.

Key Words. Echography; Female Ejaculation; G-Spot; Skene’s Glands; Female Prostate

\section{Introduction}

$\mathrm{F}$ emale genital anatomy and the physiology of female sexual function have been scientifically neglected in the past [1]. This is particularly true for orgasm, which has been described much more from a political or philosophical perspective [2] than by using scientific tools.
Female orgasm is a complex function not perfectly understood where intrapsychic, cognitive, relational, neurohormonal, vascular and anatomical factors play roles. Although literature abounds with descriptions and discussions of vaginal as opposed to clitoral orgasm [3,4] and only few studies map genital erotic sensitivity to tactile stimulation in healthy females [5], it is evident that 
some women need direct, external, clitoral stimulation whereas others may reach orgasm also by penetration and thrusting that directly stimulate the internal clitoris and vaginal wall structures and indirectly the external part of the same organ [5]. Interestingly, a study of 200 women revealed that external clitoris length varies by more than $25 \%$, demonstrating that individual differences are macroanatomic [6]. Furthermore, in cadaver studies, the internal clitoris may have individual differences bigger than 100\% [7]. Whether these differences are correlated with ability to reach orgasm is not yet established.

Other areas have been involved in the mechanism of orgasm (urethra, labia minora, Halban's fascia, periurethral glans; see [4] and references therein). On the basis of its supposedly low presence of sensory receptors, the vagina was considered as poorly responsive by Kinsey [8], and Masters and Johnson [9]. However, Gräfenberg [10], as subsequently reviewed and popularized by Ladas, Whipple, and Perry [11] (but disputed by others $[12,13])$, suggested a variable area of increased sensitivity over the urethra on the anterior vaginal wall. The urethrovaginal space (where the Halban's fascia runs [14]) seems critical, being constituted of fibro-connective tissue and large numbers of blood vessels, glands, muscular fibers, and nerve endings. The close physical proximity of the urethra and the clitoris to the anterior vaginal wall suggests an association between these anatomical structures and sexual function $[15,16]$. In fact, the anterior vaginal wall is an active organ, transmitting, during intercourse, the effect of penile thrusting in the vagina to the clitoris, by stretching the two ligaments that insert around its base [17]. As for the clitoris, microscopic examination reveals that the human vagina's anterosuperior wall differs from one subject to another [18]. The presence of pseudocavernous tissue (clitoral bulb) in the anterior vaginal mucosa is a frequent but not universal finding (86\%) [19]. Around the urethra, the existence of the prostatic embryological remnant-Skene's glands [20]—is also an anatomical variant and not a constant.

\section{Aims}

Differences in women's sexual function obviously exist and although they have been largely attributed to cultural, religious, intrapsychic and, above all, relational factors [21], it is possible that anatomical factors might be partly responsible. Thus, if "anatomy is destiny" [22], physical differences should be taken into account as a source of physiological variability in female sexual response. With these concepts in mind, the purpose of this study was to use introital ultrasonography to evaluate anatomical variability, measured as the difference in thickness of the urethrovaginal space and to correlate this variability with the presence vaginally activated orgasm.

\section{Methods}

\section{Patient Recruitment}

A cohort of 37 healthy, neurologically intact, consecutive volunteers were recruited from the normal controls of a population of women who were a part of a previously published study [23]. Approval for this study was obtained from the Internal Review Board. The women underwent physical and neurological examination (including perineal/genital inspection, vaginal, pelvic floor muscle strength, assessment of reflexes such as anal wink, bulbocavernosus and perineal-perianal sensation) and urodynamic study (UDS). All women underwent a nonstructured clinical interview at our Medical Sexology Service. The sexual history interview was conducted with each woman in a private room alone with a sexologist. Exclusion criteria consisted of drug or alcohol abuse, medications or medical conditions that might alter sexual function (e.g. diabetes), previous antiincontinence surgery or any stage of vaginal prolapse (Pelvic Organ Prolapse Quantification System, POP-Q). Subjects with sexual dysfunction were also excluded. For this purpose, a female sexual function index (FSFI) [24] total score of less than 26.55 was considered suggestive of female sexual dysfunction [25]. Specifically, only women with high scores (4 or 5) for Q.11 (bow often did you reach orgasm), Q.12 (bow difficult was it for you to reach orgasm), and Q.13 (bow satisfied were you with your ability to reach orgasm) were selected. It should be noted that these questions do not distinguish vaginal from clitoral orgasm. All subjects were exclusively heterosexual, had stable relationships (median value of 19 months [interquartile range \{IQR $\}$ 13.5-23 months]) and reported at least two acts of sexual intercourse per week, a regular menstrual cycle and that they had been sexually active within the past 6 months.

The presence of vaginal orgasm was then investigated by the same male investigator (E.A.J.) who collected the sexological history, in a separate setting. Vaginal orgasm was ascertained by the following question: "Have you ever experienced a 
vaginal orgasm?" Responses were categorized as "yes" (at least once in the past month) or "no" (never). By vaginal orgasm we mean the orgasm experienced after direct stimulation of the anterior vaginal wall by penetration, without concomitant stimulation of the external clitoris. Other investigators were blinded of these results before echographic studies. All subjects were scheduled for examination during the mid-follicular phase of their menstrual cycle.

\section{Urodynamic Evaluation}

All enrolled patients underwent uroflowmetry and urodynamic evaluation (Urobenchmark 2000/3, SI.EM., Milan, Italy) performed in duplicate. Urodynamic assessment followed the International Continence Society standards and involved water cystometry with $37^{\circ} \mathrm{C}$ normal saline solution at a filling rate of $30 \mathrm{~mL}$ per minute. A $6 \mathrm{Fr}$ double lumen transurethral catheter (Bel Bioengineering Lab, Cantù, Co, Italy) was used for infusion and recording of intravesical pressure, and 9Fr intrarectal ballon catheter (Bel Bioengineering Lab, Cantù, Co, Italy) was used for recording abdominal pressure. Electromyographic activity of pelvic floor muscle was recorded by means of surface anal skin electrodes placed at the 3 and 9 o'clock position, to check dysfunctional voiding. Pressure-flow study was carried out in sitting position. For our purposes, the following measurements were detected: detrusor pressure at maximum flow (pDetQmax), maximum flow rate (Qmax) obtained during the pressure-flow study, and post-void residual volume. The Bladder Outlet Obstruction Index (BOOI) was quantified as follows: pDetQmax-2Qmax. For the statistical analysis, the higher Qmax obtained during pressure-flow study and the related detrusor pressures were considered after performing the test twice. Impaired detrusor contractility was defined as low Qmax $(\leq 12 \mathrm{~mL} / \mathrm{s})$ and low pDetQmax $\left(\leq 10 \mathrm{cmH}_{2} \mathrm{O}\right)$ [26]. The BOO was defined as a low Qmax $(\leq 15 \mathrm{~mL} / \mathrm{s})$ and an index greater than 8 . Impaired detrusor overactivity was defined as the urodynamic evidence of involuntary detrusor contractions of $\geq 10 \mathrm{cmH}_{2} \mathrm{O}$ with volume to first contraction less than $350 \mathrm{~mL}$ [27]. The terminology used conformed with the definitions recommended by the ICS [28], except where specifically noted.

\section{Ultrasound Evaluation}

Ultrasonography was performed after UDS with the Sonoline VersaPro device (Siemens Medical System Inc., Ultrasound Group, Issaquah, WA, USA) using a $6.5 \mathrm{MHz}$ transvaginal probe, com- monly used for transvaginal evaluation. The procedure was performed by a single female investigator (F.B.) blinded to the patient's orgasm characteristics. All procedures were performed with patients in a modified Trendelemburg position and with a bladder filling volume of $300 \mathrm{~mL}$. The ultrasound evaluation was obtained by an introital approach with the transducer placed over the external urethral orifice and the transducer axis corresponding to the body axis. Care was taken not to distort the anatomy during the procedure. Jettype print photography, Polaroid photography, and video recording were used to collect all ultrasound images.

\section{Statistical Analysis}

Statistical analysis was performed using SPSS 11.0 (SPSS Inc., Chicago, IL, USA.) software. All $P$ values less than 0.05 were considered to indicate significance. All statistical tests were two-tailed. As variables were not normally distributed (ShapiroWilk test [29] $P<0.05$ ), continuous variables were presented as medians and IQR (25th and 75th percentile) and were analyzed with WilcoxonMann Whitney Rank Sum Test. For multiple comparisons of continuous variables we used the Kruskal-Wallis test with Tukey Honestly Significantly Different post boc analysis [30]. The chi-square test was used to analyze categorical variables. We also evaluated interobserver agreement by Pearson correlation. A Pearson correlation coefficient $(r)$ of less than 0.20 was considered to indicate poor agreement; $0.21-0.40$, fair agreement; 0.41-0.60, moderate agreement; 0.61-0.80, good agreement; and 0.81-1.00, excellent agreement. Correlation between variables was assessed by eta correlation [31].

\section{Main Outcome Measures}

Total urethral length and vaginal lumen were viewed in the midsagittal plane. The image was then frozen and filed digitally. Two blinded male investigators (G.L.G. and P.M.) interpreted and measured the thickness of the urethrovaginal space from the ultrasound images in random order. All ultrasound images were displayed through an image processing and analysis program (Scion Image Software version alpha 4.0.3.2, Scion Co., Frederick, MD, USA). The anatomical border between the inner smooth muscle and mucosasubmucosa layer of the urethral wall can be distinguished by ultrasonography, as can the border between the vaginal wall and its lumen, seen as a strip of low echogenicity (Figure 1). To 

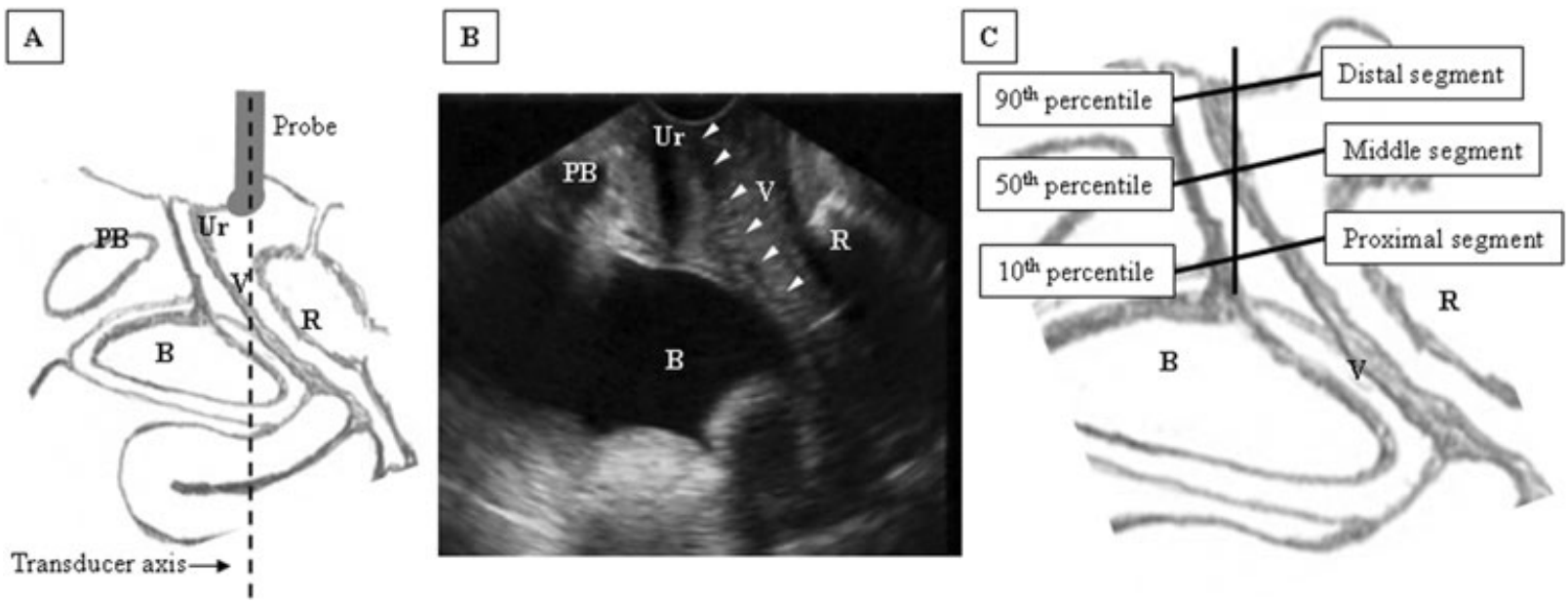

Figure 1 Schematic representation $(A)$ and introital ultrasonographic image $(B)$ of the urogenital organs. The panel (C) shows the three segments measured and the corresponding percentiles. Ur = Urethra; $\mathrm{R}=\mathrm{Rectum} ; \mathrm{B}=\mathrm{Bladder} ; \mathrm{PB}=\mathrm{Pubic}$ Bone, $\mathrm{V}=$ Vagina (also indicated by arrow heads).

standardize the procedures, all measurements were expressed in millimeters and were obtained along a line drawn between the border of the smooth muscle and mucosa-submucosa layer of the urethral wall and the border of the vaginal wall and its lumen. Measurements were taken at various percentiles of the urethra length. The internal urethral meatus was considered as the zero point and the external meatus as the 100th percentile. In the midsagittal plane, we measured the thickness of the urethrovaginal space at the 10th (proximal segment), 50th (middle segment), and 90th percentile (distal segment) of the urethra (Figure 1C). The thickness was measured three times at each location and the median value was considered for statistical purposes.

\section{Results}

\section{Clinical and Urodynamic Parameters}

Thirty-seven healthy women were considered for this study. Thirteen were excluded, six because of sexual dysfunction and seven because of menopause with or without sexual dysfunctions. Of the 24 recruitable women, four declined to participate and a total of 20 subjects were finally enrolled (Figure 2). Of these, nine reported experience of vaginal orgasm. No significant difference was noted in age, parity, hormonal pattern, menstrual cycle duration, or FSFI total score among women with and without vaginal orgasm (Table 1). The analysis of urodynamic parameters indicated that all women had both normal cystometry and pressure-flow study. None of them had clinical and urodynamic urinary incontinence or disorders of the emptying phase (i.e., bladder outlet obstruction, impaired detrusor contractility, and electromyographic evidence of dysfunctional voiding). No significant difference between the two groups was found in any urodynamic parameters (Table 1).

\section{Ultrasound Assessment}

Introital ultrasound examination was well accepted by every volunteer and no adverse events occurred during or after each session. The examination took 20 minutes (IQR 12.5-32 minutes) on average.

Figure 1 (panels A and B) shows the schematic representation and introital ultrasound image of the urogenital organs. The vagina is seen as a hypoanechoic strip, adjacent to the posterior wall of the urethra for a short distance, and running from the probe to the cervical fornix. The symphysis pubis appears as a hyperechoic shell, with a shaded cone. The rectum generates acoustic artifacts with loss of borders between the rectal and posterior vaginal wall. The urethral lumen was seen as an anechoic cylindrical structure. The striated and smooth muscle layers of the urethra cannot always be distinguished in the midsagittal plane. The mucosa and submucosa were uniformly depicted as hypoechoic structures mimicking an open lumen.

Figure 3 shows a box plot diagram of urethrovaginal space thickness, stratified by group and segment. Comparison of ultrasound images in women with and without vaginal orgasm demon- 


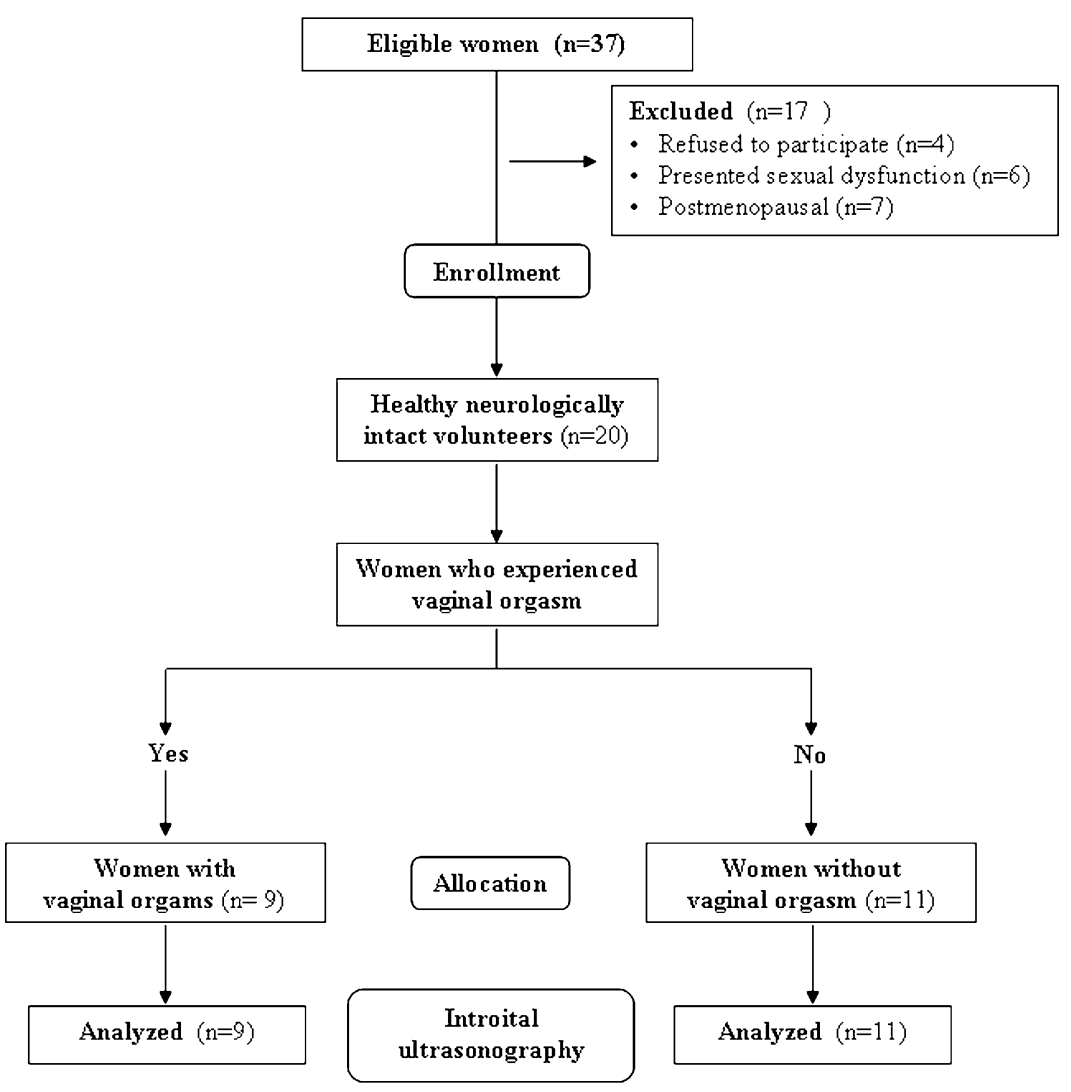

Figure 2 Study flowchart. strated a statistically significant difference in the median thickness of the urethrovaginal space $(P<0.0001)$ (Table 2), which was thinner in women without (median value $10.4 \mathrm{~mm}$; IQR 9.8 to $10.7 \mathrm{~mm}$ ) than in those with vaginal orgasm (median value $12.4 \mathrm{~mm}$; [IQR12 to $14 \mathrm{~mm}$ ]). There was no overlapping in the IQR values, suggesting that the two groups had an independent distribution for the measured parameter.
The differences in the thickness of urethrovaginal space segments were also assessed. The median thickness of distal, middle, and proximal segments was less in women without than those with vaginal orgasm. A significant difference was seen for each segment in the two groups (Table 2). A completely independent distribution was found for these variables, as evidenced by the lack of overlapping in the IQR values between the two groups. Although

Table 1 Clinical and urodynamical parameters

\begin{tabular}{|c|c|c|c|}
\hline & $\begin{array}{l}\text { Women with vaginal } \\
\text { orgasm }(\mathrm{N}=9)\end{array}$ & $\begin{array}{l}\text { Women without vaginal } \\
\text { orgasm }(\mathrm{N}=11)\end{array}$ & $P$ value* \\
\hline \multicolumn{4}{|l|}{ Clinical parameters $^{\dagger}$} \\
\hline Parity (N. of births) & $1(0-1.3)$ & $1(0-1.5)$ & 0.92 \\
\hline Menstrual cycle duration (days) & $28(26.5-30)$ & $29(27.5 .31)$ & 0.5 \\
\hline Body mass index $\left(\mathrm{Kg} / \mathrm{m}^{2}\right)$ & $21(20.6-22.9)$ & $22(2.4-23.1)$ & 0.65 \\
\hline $17 \beta$ estradiol (pmol/L) & $198(145-225)$ & $187(115-219)$ & 0.79 \\
\hline Testosterone (nmol/L) & $2.22(1.75-2.7)$ & $2.10(1.8-2.82)$ & 0.82 \\
\hline Thyrotropin (mU/L) & $1.9(1.7-2.2)$ & $2.1(2.2-1.6)$ & 0.76 \\
\hline FSFI (total score) & $29.5(27.5-32.5)$ & $29(27-33)$ & 0.77 \\
\hline \multicolumn{4}{|c|}{ Urodynamic parameters on pressure-flow study ${ }^{\dagger}$} \\
\hline Qmax (mL/s) & $20.5(19-22.5)$ & $21(20-23.5)$ & 0.18 \\
\hline$P \operatorname{detQmax}\left(\mathrm{cmH}_{2} \mathrm{O}\right)$ & $23.5(18.2-32.5)$ & $25(22.5-31.5)$ & 0.74 \\
\hline $\mathrm{BOOI}$ & $-21(-32 /-14.2)$ & $-20(-28 /-15)$ & 0.93 \\
\hline PVR (mL) & $21(17-33)$ & $23(18-34)$ & 0.45 \\
\hline
\end{tabular}

*Wilcoxon-Mann Whitney Rank Sum Test; †Median and interquartile range (25th and 75 th percentile).

$\mathrm{FSFI}=$ female sexual function index; PdetQmax = detrusor pressure at maximum flow; PVR = post-void residual; BOOI = bladder outlet obstruction index. 


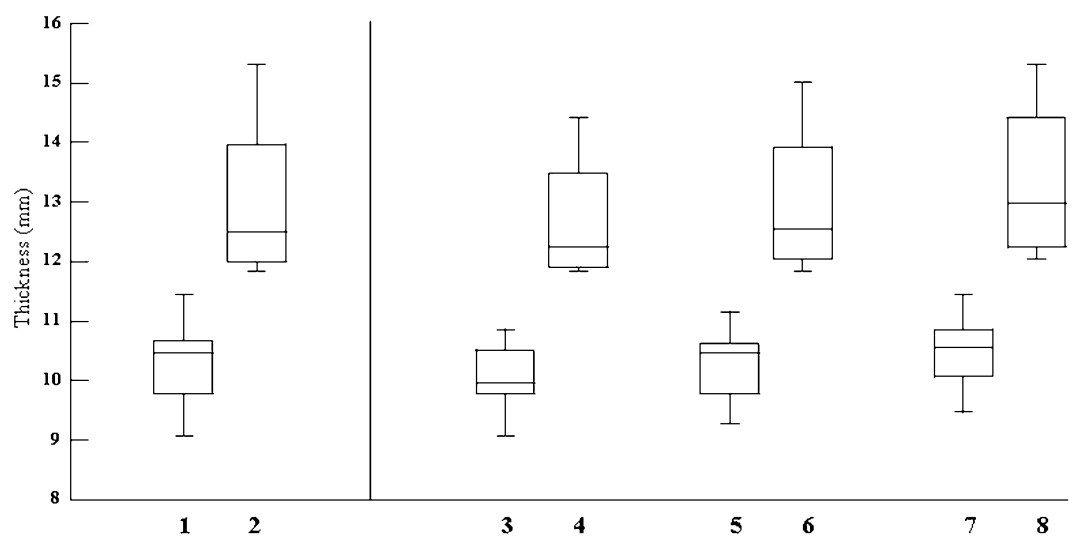

Figure 3 Box plot diagram comparing median urethrovaginal space thickness distribution of women with or without vaginal orgasm. Box represents interquartile range (IQR), bar median value and whiskers represent data points within IQR. $\mathbf{1}=$ thickness of urethrovaginal space in women without vaginal orgasm; $\mathbf{2}$ = thickness of urethrovaginal space in women with vaginal orgasm; $\mathbf{3}=$ thickness of distal urethrovaginal space in women without vaginal orgasm; $\mathbf{4}=$ thickness of distal urethrovaginal space in women with vaginal orgasm; $\mathbf{5}=$ thickness of middle urethrovaginal space in women without vaginal orgasm; $\mathbf{6}$ = thickness of middle urethrovaginal space in women with vaginal orgasm; $\mathbf{7}=$ thickness of proximal urethrovaginal space in women without vaginal orgasm; and $\mathbf{8}=$ thickness of proximal urethrovaginal space in women with vaginal orgasm.

in both groups proximal segments were thicker than the middle and distal segments, the median thickness of the different segments did not differ significantly within each group for women with $(P=0.39)$ and without vaginal orgasm, $(P=0.32)$.

Interobserver agreement between the two investigators performing the urethrovaginal space measurement was excellent $(r=0.87 ; P<0.001)$.

Correlation analysis was estimated for those variables that significantly differed between two groups. This analysis, performed to determine interdependencies between the reported presence of a vaginal orgasm and the thickness of the urethrovaginal space, demonstrated a significant correlation between the presence of vaginal orgasm and the thickness of the urethrovaginal space. Women with a thicker urethrovaginal space were more likely to experience vaginal orgasm $(r=0.884 ; P=0.015)$ (Table 3).

Correlation analysis, performed by stratifying the urethrovaginal space by segment, showed a direct and significant correlation between the thickness of each segment and the presence of vaginal orgasm. The best correlation was found with the distal segment of the urethrovaginal space $(r=0.863 ; P<0.0001)$.

\section{Discussion}

For cultural and historical reasons, scientific knowledge of female sexual function is still in its infancy. Here, we describe for the first time the use of a simple tool-introital ultrasonography-to characterize the thickness of the urethrovaginal space and correlate this with the presence or absence of vaginal orgasm. Although the number of analyzed subjects was small, the strict selection criteria render this population unique for a study of this kind. To eliminate possible confounders and improve the reproducibility of urethrovaginal space measurements, we excluded patients with clinical and urodynamic urinary incontinence [32],

Table 2 Thickness of the urethrovaginal space in women with or without vaginal orgasm

\begin{tabular}{|c|c|c|c|c|}
\hline & & $\begin{array}{l}\text { Women without vaginal } \\
\text { orgasm }(N=11)\end{array}$ & $\begin{array}{l}\text { Women with vaginal } \\
\text { orgasm }(\mathrm{N}=9)\end{array}$ & $P$ value \\
\hline Median thickness of urethrovaginal space* & & $10.4(9.8-10.7)$ & $12.4(12.0-14.0)$ & $<0.0001^{\dagger}$ \\
\hline \multirow{3}{*}{ Median thickness of urethrovaginal space segments* } & Distal & $9.9(9.7-10.6)$ & $12.2(11.9-13.5)$ & $<0.0001^{\ddagger}$ \\
\hline & Middle & $10.4(9.8-10.6)$ & $12.5(12.0-13.9)$ & $<0.0001^{\ddagger}$ \\
\hline & Proximal & $10.6(10.1-11.9)$ & $12.9(12.3-14.4)$ & $<0.0001^{\ddagger}$ \\
\hline
\end{tabular}

*Median and interquartile range (25th and 75th percentile).

tWilcoxon-Mann Whitney Rank Sum Test.

łKruskal-Wallis test with Tukey HSD post hoc analysis. 
Table 3 Correlation between thickness of urethrovaginal space and vaginal orgasm

\begin{tabular}{llc}
\hline Correlation & $\begin{array}{l}\text { Correlation } \\
\text { coefficient }^{\star}\end{array}$ & $P$ value \\
\hline - Thickness of urethrovaginal space vs. & 0.884 & 0.015 \\
vaginal orgasm & & \\
- Distal segment vs. vaginal orgasm & 0.863 & $<0.0001$ \\
- Middle segment vs. vaginal orgasm & 0.801 & $<0.0001$ \\
- Proximal segment vs. vaginal orgasm & 0.810 & $<0.0001$ \\
\hline
\end{tabular}

${ }^{\star}$ Eta correlation

idiopathic detrusor overactivity, and micturition disorders [33], as well as postmenopausal patients and those with sexual dysfunction. As female genital anatomy is affected by estrogen and androgen activity [34], we also standardized the day of menstrual cycle. The measurement sites were also strictly uniform.

These results raise several questions. What anatomical structures did we measure? Does urethrovaginal space thickness differ in all women with vaginal orgasm, or have we identified a subset of patients? Have we measured the controversial $\mathrm{G}$-spot in vivo?

Ultrasonography is a widely used tool for the assessment of the female urogenital tract, but its spatial and structural resolution remains much lower [35] than other imaging techniques [34]. Consequently, the anatomical structures within the urethrovaginal space cannot be fully resolved by ultrasonography. Gräfenberg described an erogenous zone located in the anterior vaginal wall [10] and subsequent studies have correlated the focus of female sensitivity with the external urethral sphincter [11]. Effectively, we made our measurements where the urethra is surrounded by the corpora cavernosa of the bulb of the clitoris-rich in nitric oxide synthase and type $\mathrm{V}$ phosphodiesterase activity [19], [36] — and by the exocrine, the Prostatic Specific Antigen-expressing Skene's glands and a plethora of nerve endings [18,37]. However, histological studies have demonstrated clear interindividual differences $[18,19]$. The variability in female orgasm [38] could be at least partially attributed to differences in the presence, extension and reciprocal relationship of these anatomical structures. As the anatomy of the external clitoris changes [6], it is possible that some women may have more extensive clitoral bulbar tissue, exocrine glands, (highly variable embryological remnants), and nerves embedded in the anterior vaginal wall than others, such that they can achieve orgasm by direct stimulation of the urethrovaginal space and not only by stimulation of the external clitoris. Further well-controlled studies, based on the method here described, on much larger samples are needed to confirm the possible correlation between the anatomy of the anterior vaginal wall and vaginal orgasm. As the clitoris [39] and the Skene's glands are under androgen control, we are currently measuring differences in the urethrovaginal space in hirsute women before and after antiandrogen therapy, in women taking various estroprogestins, and in women reporting the much-debated phenomenon of female ejaculation (FE) [40,41]. Interestingly, women who experience FE may have normal voiding patterns, no bothersome incontinence symptoms, and no demonstrable detrusor overactivity [42]. In comparison with women not experiencing $\mathrm{FE}$, this suggests anatomic differences, as here demonstrated.

Another interesting finding is that the thickness of all three urethrovaginal segments measured (Figure 1) correlates with reported vaginal orgasm, with the best correlation found with the distal segment. These data could be of particular interest if observed in the light of the latest anatomical and sexual knowledge, as there is now evidence that the clitoris is related to the distal third of the urethra in the perivaginal space [16].

To date, there are no pharmacological agents trials proven to be beneficial beyond placebo in enhancing orgasmic function in women diagnosed with the not uncommon female orgasmic disorder [43]. More research is needed in understanding physiology of female orgasm. Although we present herein anatomical evidences, our data should be considered as preliminary and interpreted cautiously, given the small sample size. Additionally, accurate placement of the measuring cursor was more difficult when structural borders were indistinct, even if interobserver agreement was excellent. Furthermore, the structural measurements made in this study were for comparative purposes and not intended to establish standard values.

The self-reported nature of presence or absence of vaginal orgasm is another strong limitation of our findings. Formal demonstration of the orgasm is theoretically possible, but the majority of the studies on that topic are based on the administration of inventories and questionnaires [44].

The most interesting finding of our study is the evidence that women who experience vaginal orgasm have an urethrovaginal space thicker than those who do not. However, our data cannot directly demonstrate that the thickness of an 
anatomical "space" may generate a mechanism that can be related to the creation of an orgasm. But, in conclusion, the results here presented allow us to speculate that there may be a functional correlation between the thickness of urethrovaginal space, or G-spot, and the ability to experience the vaginal orgasm.

\section{Acknowledgments}

Our compliments and gratitude to Ms. Marie-Hélène Hayles and Dr. Rosaria Caruso for adapting their English expertise to our needs. This paper was partially supported by Italian Ministry of Research and Education PRIN grants and by an unrestricted grant from Pfizer Italia.

Corresponding Author: Emmanuele Jannini, MD, School of Sexology, Department of Experimental Medicine, University of L'Aquila, Via Vetoio, Coppito, L'Aquila, 67100, Italy. Tel: (+39) (0) 862 433530; Fax: (+39) (0) 862 433523; E-mail: jannini@univaq.it

Conflict of Interest: None declared.

\section{References}

1 Segraves R, Balon R, Clayton A. Proposal for changes in diagnostic criteria for sexual dysfunctions. J Sex Med 2007;4:567-80.

2 Singer J, Singer I. Types of female orgasm. J Sex Res 1972;8:255-67.

3 Levin RJ. Sexual desire and the deconstruction and reconstruction of the human female sexual response model of Masters and johnson. In: Everaerd W, Laan H, Both S, eds. Sexual appetite, desire and motivation: Energetics of the sexual system. Amsterdam: Royal Netherlands Academy of Arts and Sciences; 2001:63-93.

4 Levin RJ. The physiology and pathophysiology of the female orgasm. In: Goldstein I, Meston CM, Davis SR, Traish AM, eds. Women's sexual function and dysfunction. London: Taylor \& Francis; 2006: 228-35.

5 Gruenwald I, Lowenstein L, Gartman I, Vardi Y. Physiological changes in female genital sensation during sexual stimulation. J Sex Med 2007;4:390-4.

6 Verkauf BS, Von Thron J, O'Brien WF. Clitoral size in normal women. Obstet Gynecol 1992;80:41-4.

7 O'Connell HE, Sajeevan KV. Anatomy of female genitalia. In: Goldstein I, Meston CM, Davis SR, Traish AM, eds. Women's sexual function and dysfunction. London: Taylor \& Francis; 2006:105-12.

8 Kinsey AC, Pomeroy WB, Martin CE, Gebhard PH. Sexual behaviour in the human female. Philadelphia, PA: W.B. Sanders Co.; 1953.

9 Masters WH, Johnson VE. Human sexual response. Boston, MA: Little, Brown; 1966.
10 Grafenberg E. The role of the urethra in female orgasm. Int J Sexol 1950;3:145-8.

11 Ladas AK, Whipple B, Perry J. The G-spot and other recent discoveries about human sexuality. New York: Holt, Reinehart \& E Wiston; 1982.

12 Hines TM. The G-spot: A modern gynecologic myth. Am J Obstet Gynecol 2001;185:359-62.

13 Pauls R, Mutema G, Segal J, Silva WA, Kleeman S, Dryfhout Ma V, Karram M. A prospective study examining the anatomic distribution of nerve density in the human vagina. J Sex Med 2006;3:979_ 87.

14 Hoang NM, Smadja A, Herve de Sigalony JP. [The reality and usefulness of Halban's fascia]. J Gynecol Obstet Biol Reprod (Paris) 1991;20:51-9.

15 O'Connell HE, Hutson JM, Anderson CR, Plenter RJ. Anatomical relationship between urethra and clitoris. J Urol 1998;159:1892-7.

16 O'Connell HE, Sanjeevan KV, Hutson JM. Anatomy of the clitoris. J Urol 2005;174: 1189-95.

17 Ingelman-Sundberg A. The anterior vaginal wall as an organ for the transmission of active forces to the urethra and the clitoris. Int Urogynecol J Pelvic Floor Dysfunct 1997;8:50-1.

18 D'amati G, di Gioia CR, Proietti Pannunzi L, Pistilli D, Carosa E, Lenzi A, Jannini EA. Functional anatomy of the human vagina. $\mathrm{J}$ Endocrinol Invest 2003;26(3 suppl):92-6.

19 D'amati G, di Gioia CR, Bologna M, Giordano D, Giorgi M, Dolci S, Jannini EA. Type 5 phosphodiesterase expression in the human vagina. Urology 2002;60:191-5.

20 Zaviacic M, Ablin RJ. The female prostate and prostate-specific antigen. Immunohistochemical localization, implications of this prostate marker in women and reasons for using the term "prostate" in the human female. Histol Histopathol 2000;15:13142.

21 Fourcroy JL. Customs, culture, and traditionWhat role do they play in a woman's sexuality? J Sex Med 2006;3:954-9.

22 Freud S. Some psychical consequences of the anatomical distinction between the sexes the standard edition of the complete psychological works of Sigmund Freud. London: The Hogarth Press and The Institute of Psychoanalysis; 1995.

23 Gravina GL, Costa AM, Ronchi P, Galatioto GP, Luana G, Vincentini C. Bladder outlet obstruction index and maximal flow rate during urodynamic study as powerful predictors for the detection of urodynamic obstruction in women. Neurourol Urodyn 2007;26:247-53.

24 Rosen R, Brown C, Heiman J, Leiblum S, Meston C, Shabsigh R, Ferguson D, D'agostino R Jr. The Female Sexual Function Index (FSFI): A multidimensional self-report instrument for the assessment of female sexual function. J Sex Marital Ther 2000;26:191-208. 
25 Corona G, Jannini EA, Maggi M. Inventories for male and female sexual dysfunctions. Int J Impot Res 2005.

26 Defreitas GA, Lemack GE, Zimmern PE. Nonintubated uroflowmetry as a predictor of normal pressure flow study in women with stress urinary incontinence. Urology 2003;62:905-8.

27 Lee JY, Kim HW, Lee SJ, Koh JS, Suh HJ, Chancellor MB. Comparison of doxazosin with or without tolterodine in men with symptomatic bladder outlet obstruction and an overactive bladder. BJU Int 2004;94:817-20.

28 Weber AM, Abrams P, Brubaker L, Cundiff G, Davis G, Dmochowski RR, Fischer J, Hull T, Nygaard I, Weidner AC. The standardization of terminology for researchers in female pelvic floor disorders. Int Urogynecol J Pelvic Floor Dysfunct 2001;12:178-86.

29 Shapiro SS, Wilk MB. An analysis of variance test for normality (complete samples). Biometrika 1965;52:591-611.

30 Neter J, Kutner MH, Nachtsheim CJ, Wasserman W. Applied linear statistical models. New York: McGraw-Hill; 1996.

31 Cohen J. Statistical power analysis for the behavioral sciences. S. Hillsdale, NJ: Lawrence Erlbaum Association; 1988.

32 Kondo Y, Homma Y, Takahashi S, Kitamura T, Kawabe K. Transvaginal ultrasound of urethral sphincter at the mid urethra in continent and incontinent women. J Urol 2001;165:149-52.

33 Major H, Culligan P, Heit M. Urethral sphincter morphology in women with detrusor instability. Obstet Gynecol 2002;99:63-8.

34 Suh DD, Yang CC, Cao Y, Garland PA, Maravilla KR. Magnetic resonance imaging anatomy of the female genitalia in premenopausal and postmenopausal women. J Urol 2003;170:138-44.
35 Tunn R, Petri E. Introital and transvaginal ultrasound as the main tool in the assessment of urogenital and pelvic floor dysfunction: An imaging panel and practical approach. Ultrasound Obstet Gynecol 2003;22:205-13.

36 Uckert S, Ellinghaus P, Albrecht K, Jonas U, Oelke $M$. Expression of messenger ribonucleic acid encoding for phosphodiesterase isoenzymes in human female genital tissues. J Sex Med 2007;4:1604-9.

37 Jannini EA, d'Amati G, Lenzi A. Histology and immunohistochemical studies of female genital tissue. In: Goldstein I, Meston C, Davis S, Traish A, eds. Women's sexual function and dysfunction: Study, diagnosis and treatment. London: Taylor and Francis; 2006:125-33.

38 Andersen BL, Cyranowski JM. Women's sexuality: Behaviors, responses, and individual differences. J Consult Clin Psychol 1995;63:891-906.

39 Traish AM, Kim N, Min K, Munarriz R, Goldstein I. Role of androgens in female genital sexual arousal: Receptor expression, structure, and function. Fertil Steril 2002;77(4 suppl):S11-8.

40 Darling CA, Davidson JK Sr, Conway-Welch, C. Female ejaculation: Perceived origins, the Grafenberg spot/area, and sexual responsiveness. Arch Sex Behav 1990;19:29-47.

41 Wimpissinger F, Stifter K, Grin W, Stackl W. The female prostate revisited: Perineal ultrasound and biochemical studies of female ejaculate. J Sex Med 2007;4:1388-93; discussion 93.

42 Cartwright R, Elvy S, Cardozo L. Do women with female ejaculation have detrusor overactivity? J Sex Med 2007;4:1655-8.

43 Meston CM, Hull E, Levin RJ, Sipski M. Disorders of orgasm in women. J Sex Med 2004;1:66-8.

44 Meston CM, Levin RJ, Sipski ML, Hull EM, Heiman JR. Women's orgasm. Annu Rev Sex Res 2004;15:173-257. 